\title{
Article \\ Effect of Spatial Distribution of nZVI on the Corrosion of nZVI Composites and Its Subsequent Cr(VI) Removal from Water
}

\author{
Yixuan Li, Shuangqiu Huang, Yaqin Song, Xinfang Zhang, Sijia Liu and Qiong Du *
}

School of Engineering, China Pharmaceutical University, Nanjing 211198, China; liyixuan_1117@163.com (Y.L.); 2111904034@e.gzhu.edu.cn (S.H.); songyq_11@126.com (Y.S.); zhxf20@163.com (X.Z.); liusijia_98@163.com (S.L.)

* Correspondence: duqiong116@163.com; Tel.: +86-25-8618-5190

Citation: Li, Y.; Huang, S.; Song, Y.; Zhang, X.; Liu, S.; Du, Q. Effect of Spatial Distribution of nZVI on the Corrosion of nZVI Composites and Its Subsequent Cr(VI) Removal from Water. Nanomaterials 2022, 12, 494. https://doi.org/10.3390/nano12030494

Academic Editors: Tsung-Shine Ko, Giuseppe Lazzara and George Z. Kyzas

Received: 19 November 2021

Accepted: 27 January 2022

Published: 30 January 2022

Publisher's Note: MDPI stays neutral with regard to jurisdictional claims in published maps and institutional affiliations.

Copyright: (c) 2022 by the authors Licensee MDPI, Basel, Switzerland. This article is an open access article distributed under the terms and conditions of the Creative Commons Attribution (CC BY) license (https:// creativecommons.org/licenses/by/ $4.0 /)$.

\begin{abstract}
There have been many studies on contaminant removal by fresh and aged nanoscale zero-valent iron (nZVI), but the effect of spatial distribution of nZVI on the corrosion behavior of the composite materials and its subsequent $\mathrm{Cr}(\mathrm{VI})$ removal remains unclear. In this study, four types of D201-nZVI composites with different nZVI distributions (named D1, D2, D3, and D4) were fabricated and pre-corroded in varying coexisting solutions. Their effectiveness in the removal of $\mathrm{Cr}(\mathrm{VI})$ were systematically investigated. The results showed acidic or alkaline conditions, and all coexisting ions studied except for $\mathrm{H}_{2} \mathrm{PO}_{4}{ }^{-}$and $\mathrm{SiO}_{3}{ }^{2-}$ enhanced the corrosion of nZVI. Additionally, the $\mathrm{Cr}(\mathrm{VI})$ removal efficiency was observed to decrease with increasing nZVI distribution uniformity. The corrosion products derived from nZVI, including magnetite, hematite, lepidocrcite, and goethite, were identified by XRD. The XPS results suggested that the $\mathrm{Cr}(\mathrm{VI})$ and $\mathrm{Cr}(\mathrm{III})$ species coexisted and the $\mathrm{Cr}$ (III) species gradually increased on the surface of the pre-corroded D201-nZVI with increasing iron distribution uniformity, proving $\mathrm{Cr}(\mathrm{VI})$ removal via a comprehensive process including adsorption/coprecipitation and reduction. The results will help to guide the selection for nZVI nanocomposites aged under different conditions for environmental decontamination.
\end{abstract}

Keywords: nanoscale zero-valent iron (nZVI); pre-corrosion; $\mathrm{Cr}(\mathrm{VI})$ adsorption and reduction; corrosion products

\section{Introduction}

As an environmentally functional material, zero-valent iron (ZVI) has been widely used for in situ pollution remediation because of its high reactivity, low price, and environmental friendliness [1]. Compared with ZVI, nanoscale zero-valent iron (nZVI) has a higher specific surface area and high reactivity. Nevertheless, the weaknesses, including poor stability, difficult separation, and rapid passivation, remarkably limit the effectiveness of nZVI and its practical application [2]. To counteract these drawbacks, an effective approach is to immobilize nZVI into porous materials such as activated carbon [3], bentonite [4], kaolinite [5], chitosan [6], and exchange resin [7], which can be used as a carrier to support nZVI with good mechanical strength and adjustable pore structure.

ZVI and its modifications could effectively degrade or transform several water pollutants such as persistent pollutants [8], heavy metal [9-11], coloring dyestuff [12], and phosphate [13]. However, it is necessary to consider the corrosion of ZVI while focusing on the removal of contaminants, because there is a certain time interval between the synthesis and practical application of ZVI $[1,14]$. ZVI easily reacts with oxygen and water molecules that could consume electrons because of its high activity and low electron selectivity [15], leading to corrosion product iron oxides or hydroxides forming on the surface of ZVI, such as $\mathrm{Fe}_{3} \mathrm{O}_{4}, \mathrm{Fe}_{2} \mathrm{O}_{3}, \mathrm{Fe}(\mathrm{OH})_{3}$, and $\gamma$-FeOOH $[16,17]$. In other words, ZVI employed for practical environment remediation has been pre-corroded under different conditions. The presence of corrosion products might increase the non-reduction process. The degree to which the reactivity of ZVI decreases depends on the thickness and composition of the 
corrosion product on the ZVI surface [17-19]. Many factors affect the corrosion degree of ZVI, such as the solution chemistry, exposure time, and structure [20-22]. Nowadays, several studies have been carried out on the corrosion of ZVI nanoparticles in the process of pollutant removal $[23,24]$. Nevertheless, little is known about the influence of supported nZVI structure in different pre-corrosion conditions on the removal of contaminants. Therefore, systematic investigation is required to explore the effect of the pre-corrosion of supported nZVI with different structures and to provide a potential method to improve the decontamination performance of nZVI.

In this study, $\mathrm{Cr}(\mathrm{VI})$ was used as a probe to evaluate the performance of nanocomposite. A macroporous anion exchange resin (D201) was utilized as the support for nZVI to improve the dispersion, and the synthetic nanocomposite (D201-nZVI) was employed to remove $\mathrm{Cr}(\mathrm{VI})$ from water. We systematically investigated the removal performance of $\mathrm{Cr}(\mathrm{VI})$ by pre-corroded D201-nZVI with different iron distributions. Moreover, the influences on D201-nZVI under different pre-corrosion conditions (e.g., ions, initial pH, dissolved oxygen (DO), corrosion time, and humic acid) were studied on $\mathrm{Cr}(\mathrm{VI})$ removal. The chemical compositions of D201-nZVI before and after pre-corrosion were analyzed using X-ray diffraction (XRD) and X-ray photoelectron spectroscopy (XPS), respectively. In addition, the removal mechanism by the pre-corroded D201-nZVI was elucidated.

\section{Materials and Methods}

\subsection{Materials and Chemicals}

The D201 resin, styrene-diethylene benzene copolymer with quaternary ammonium group (mean diameter of $0.7-0.8 \mathrm{~mm}$ ) was purchased from Hangzhou Zhengguang Technology, Co., Ltd. (Hangzhou, China). D201 was washed with 1.5 M NaOH, 1.5 M HCl, distilled water, and ethanol to remove the potential residual impurities and dried at $40{ }^{\circ} \mathrm{C}$ for $24 \mathrm{~h}$ before use. $\mathrm{FeCl}_{3} \cdot 6 \mathrm{H}_{2} \mathrm{O}, \mathrm{MgCl}_{2} \cdot 6 \mathrm{H}_{2} \mathrm{O}, \mathrm{NaH}_{2} \mathrm{PO}_{4} \cdot 2 \mathrm{H}_{2} \mathrm{O}, \mathrm{Na}_{2} \mathrm{SiO}_{3}$, and diphenylcarbazide were purchased from Sinopharm Chemical Reagent Co., Ltd. (Shanghai, China) $\mathrm{K}_{2} \mathrm{Cr}_{2} \mathrm{O}_{7}$, $\mathrm{NaCl}, \mathrm{CaCl}_{2}, \mathrm{Na}_{2} \mathrm{SO}_{4}$, and $\mathrm{NaOH}$ were purchased from Xilong Science Co., Ltd. (Shantou, China). $\mathrm{HCl}, \mathrm{NaNO}_{3}$, and $\mathrm{NaHCO}_{3}$ were purchased from Nanjing Chemical Reagent Co., Ltd. (Nanjing, China). $\mathrm{KCl}$ and $\mathrm{KBH}_{4}$ were purchased from Shanghai Lingfeng Chemical Reagent Co., Ltd. (Shanghai, China). Anhydrous ethanol was purchased from Shanghai Titan Scientific Co., Ltd. (Shanghai, China). All chemicals were of analytical grade and all solutions were prepared with ultrapure water.

\subsection{Synthesis of D201-nZVI}

Four types of D201-nZVI nanocomposites were synthesized using an ion exchange and liquid-phase reduction method, as reported in the previously published literature [25]. In brief, it can be summarized as follows: (1) $1 \mathrm{~g}$ D201 resin was added to $100 \mathrm{~mL} \mathrm{FeCl}_{3}-\mathrm{HCl}$ solution $\left(1 \mathrm{M} \mathrm{FeCl}_{3} \cdot 6 \mathrm{H}_{2} \mathrm{O}, 1 \mathrm{M} \mathrm{HCl}\right.$, saturated $\mathrm{NaCl}$ and $10 \%$ ethanol), stirring for $6 \mathrm{~h}$ at $25{ }^{\circ} \mathrm{C}$ to achieve the preloading of $\mathrm{Fe}$ (III) onto the inner surface of D201 by ion exchange; (2) after washing with absolute ethanol, the resin preloaded-Fe (III) was reduced into nZVI with different distributions using $100 \mathrm{~mL} \mathrm{KBH}_{4}$ solutions with mass concentrations of $0.9 \%, 1.8 \%, 3.6 \%$, and $7.2 \%$, named D1, D2, D3, and D4, respectively. The D201-nZVI nanocomposites were filtered with 50-mesh gauze and washed with deionized water. Black spherical D201-nZVI nanocomposites were dried in a vacuum oven (DZF-6020, Xinmiao, Shanghai, China) at $50{ }^{\circ} \mathrm{C}$.

\subsection{Pre-Corrosion of D201-nZVI}

Here, $0.1 \mathrm{~g}$ D201-nZVI was added in the Erlenmeyer flask with $100 \mathrm{~mL}$ ultrapure water at $25{ }^{\circ} \mathrm{C}$ using a constant temperature shaker (Taicang Qiangle Experimental Equipment Co., Ltd., Suzhou, China). The corrosion time was set $0,24,48$, and $120 \mathrm{~h}$, respectively. Moreover, pre-corroded D201-nZVI under different pre-corrosion conditions (e.g., ions, initial $\mathrm{pH}$, dissolved oxygen (DO), corrosion time, and humic acid) were synthesized. The initial $\mathrm{pH}$ of the corrosion solution was adjusted to 3, 6, and 9 with $1 \mathrm{M} \mathrm{HCl}$ or $1 \mathrm{M} \mathrm{NaOH}$. 
The oxygenated corrosion solution with DO content of $8.4 \mathrm{mg} / \mathrm{L}$ and deoxidizing solution with DO content of $1.6 \mathrm{mg} / \mathrm{L}$ were prepared as corrosion solution. The coexisting ions of the corrosion solution include $10 \mathrm{mmol} / \mathrm{L} \mathrm{NaCl}, 10 \mathrm{mmol} / \mathrm{L} \mathrm{Na}_{2} \mathrm{SO}_{4}, 10 \mathrm{mmol} / \mathrm{L} \mathrm{NaNO}_{3}$, $10 \mathrm{mmol} / \mathrm{L} \mathrm{NaHCO}, 10 \mathrm{mmol} / \mathrm{L} \mathrm{KH}_{2} \mathrm{PO}_{4}$, and $10 \mathrm{mmol} / \mathrm{L} \mathrm{Na}_{2} \mathrm{SiO}_{3}$, and the mixture of above anions or $10 \mathrm{mmol} / \mathrm{L} \mathrm{NaCl}, 10 \mathrm{mmol} / \mathrm{L} \mathrm{KCl}, 10 \mathrm{mmol} / \mathrm{L} \mathrm{CaCl}_{2}$, and $10 \mathrm{mmol} / \mathrm{L}$ $\mathrm{MgCl}_{2}$, and the mixture of above cations), respectively (considering the $\mathrm{Cr}(\mathrm{VI})$ removal had insignificant effects with the increase of ion strength to $100 \mathrm{mmol} / \mathrm{L}$ (Figure S1), we set the ionic strength as $10 \mathrm{mmol} / \mathrm{L}$ in coexisting ions tests). The humic acid concentrations of corrosion solution were set to $0,20,40$, and $100 \mathrm{mg} / \mathrm{L}$, respectively. After pre-corrosion, the pre-corroded D201-nZVI were filtered and transferred to a clean Erlenmeyer flask for the batch experiments.

\subsection{Batch Experiment}

In the static experiment, a total of $0.1 \mathrm{~g}$ pre-corroded D201-nZVI under different solutions was added to $100 \mathrm{~mL}$ of $150 \mathrm{mg} / \mathrm{L} \mathrm{Cr}(\mathrm{VI})$ solution and shaken at $25^{\circ} \mathrm{C}$ for $24 \mathrm{~h}$. In the kinetics experiment, $0.1 \mathrm{~g}$ pre-corroded D201-nZVI from pure $\mathrm{H}_{2} \mathrm{O}$ (corrosion time of 0 and $48 \mathrm{~h}$ ) was added to a three-necked flask containing $500 \mathrm{~mL}$ of $30 \mathrm{mg} / \mathrm{L} \mathrm{Cr}(\mathrm{VI})$ and stirred at $160 \mathrm{rpm}$. The $\mathrm{Cr}(\mathrm{VI})$ solution was sampled and analyzed several times. All experiments were performed in triplicate.

\subsection{Material Characterization}

Images of the iron distribution of fresh D1, D2, D3, and D4 were obtained using scanning electron microscopy (SEM, Quanta 400 FEG, FEG, OR, USA) with energy diffraction spectrum (EDS, Bruker, Karlsruhe, Germany) analyses. The BET surface areas of the fresh D1-D4 were measured using the $\mathrm{N}_{2}$ adsorption and desorption test (ASAP 2460, Micromeritics, Norcross, GA, USA). XPS (Thermo Scientific ESCALAB 250Xi, Thermo Scientific, Boston, MA USA) with a monochromatized $\mathrm{Al} \mathrm{K \alpha} \mathrm{X}$-ray source was used to analyze the pre-corroded D201-nZVI in the $\mathrm{H}_{2} \mathrm{O}$ system after the $\mathrm{Cr}(\mathrm{VI})$ removal and the results were processed using XPSPEAK 41 software (version: 4.1). The X-ray diffraction (XRD) patterns of fresh D201-nZVI and pre-corroded D201-nZVI in the different coexisting solutions were recorded using a D8 ADVANCE XRD system (D8 Bruker Adv., Oberkochen, Germany).

\subsection{Analytic Methods}

Fe(III) was measured with phenanthroline colorimetry using a 752 UV-Visible spectrophotometer (YOKE Instrument, Shanghai, China) at $510 \mathrm{~nm}$. Then, $0.1 \mathrm{~g}$ D201-nZVI was added to $50 \mathrm{~mL} \mathrm{HNO}_{3}$ solution with a $10 \%$ mass concentration and reacted at $25{ }^{\circ} \mathrm{C}$ for $12 \mathrm{~h}$ [25]. The four types of D201-nZVI have almost the same iron content. The iron contents of D1, D2, D3, and D4 were determined to be $13.81 \%, 13.36 \%, 14.05 \%$, and $13.75 \%$, respectively. The concentration of $\mathrm{Cr}(\mathrm{VI})$ was measured with diphenylcarbazide colorimetry using a $752 \mathrm{UV}$-Visible spectrophotometer at $540 \mathrm{~nm}$ [26].

\section{Results and Discussion}

\subsection{Characterization of D201-nZVI}

As demonstrated in Figure 1a,b, the image of D1 showed the circular distribution of iron in the periphery of the spherical resin particles, as visualized through the SEM-EDX of iron element along the cross section and diameter of fresh D1-D4 samples. With the increase in reductant $\left(\mathrm{KBH}_{4}\right)$ concentration from $0.9 \%$ to $7.2 \%$, the iron distribution of D201nZVI gradually shifted from the outside of the resin to the core area, indicating that the uniformity of the iron distribution in the resin notably improved from D1 to D4. Figure 1c shows the TEM image of fresh D1-D4 samples, which permitted the direct observation of microstructural features of this material. It could also be seen the details of four types of D201-nZVI at $100 \mathrm{~nm}$ that demonstrated nanoscale iron were well dispersed on the surface and interior of the D201 resin. The specific surface area was 9.75, 14.70, 15.63, and $16.40 \mathrm{~m}^{2} \mathrm{~g}^{-1}$ for D1, D2, D3, and D4, respectively (Table S1). For the D1-D4 composites, the 
increase in Fe distributions' uniformity resulted in a significant increase in BET surface area, possibly due to the loading of the nZVI with higher specific surface areas. A more uniform distribution of $\mathrm{nZVI}$ inside the nanocomposite was favorable to restrict the aggregation of freshly formed nZVI. They could provide a more accessible surface and, thereby, increase the BET surface area.

(a)

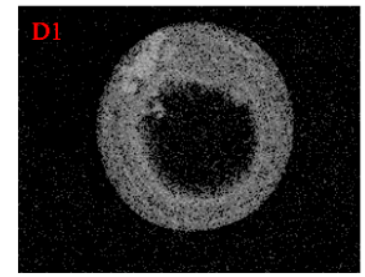

(b)

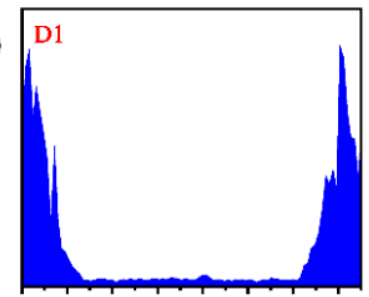

$0 \longdiv { 1 0 0 2 0 0 3 0 0 4 0 0 5 0 0 6 0 0 7 0 0 }$

Position along the diameter $(\mu \mathrm{m})$

(c)

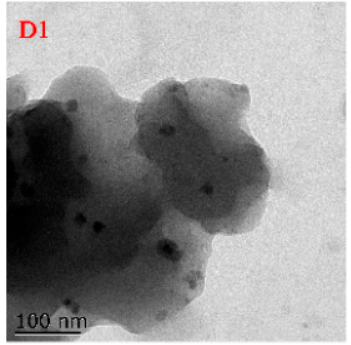

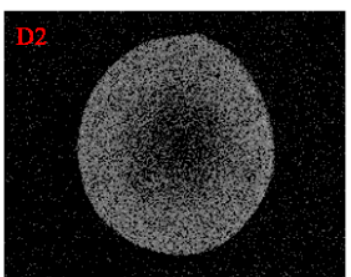

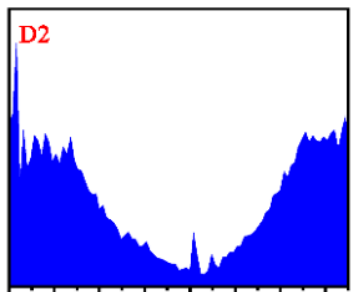

100200300400500600700 Position along the diameter $(\mu \mathrm{m})$

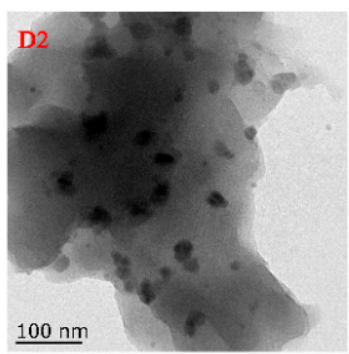

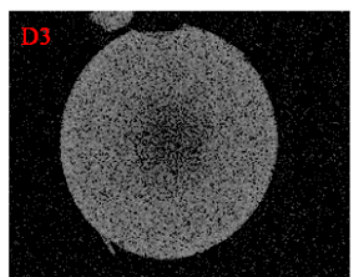
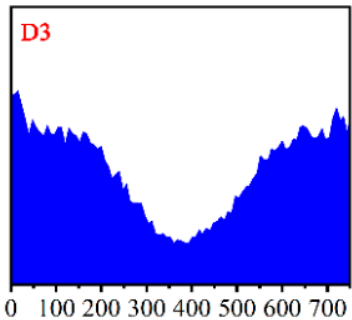

Position along the diameter $(\mu \mathrm{m})$

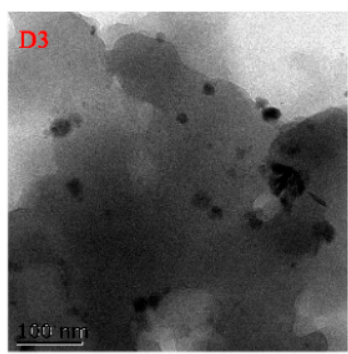

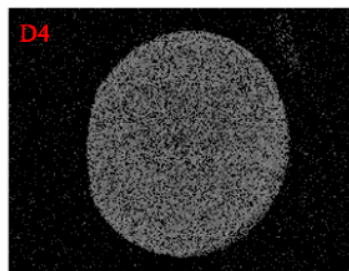

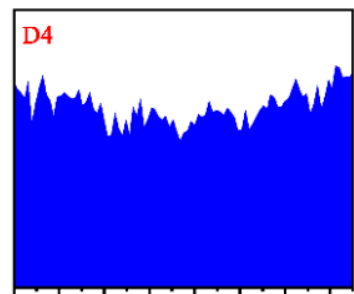

$0 \quad 100200300400500600700$ Position along the diameter $(\mu \mathrm{m})$

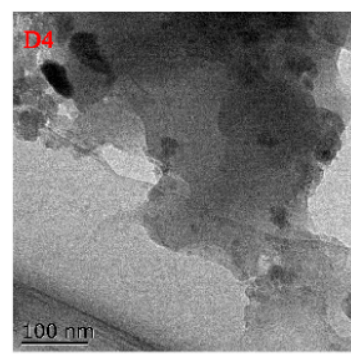

Figure 1. SEM-EDS spectra of elemental Fe mapping (a) and lines (b) in the cross section, and TEM images (c) of fresh D1, D2, D3, and D4.

The chemical components of D201-nZVI were further identified by XRD analysis. The XRD patterns for fresh D1, D2, D3, and D4 are shown in Figure 2a. The broad peaks at $44.8^{\circ}$ were observed in the all types of D201-nZVI XRD patterns, indicating a small particle size and the existence of crystalline metallic $\mathrm{Fe}^{0}$ (JCPDS 06-0696) [1,7]. There was no significant difference in the peak of ZVI in the four types of fresh D201-nZVI, which might be caused by the dispersion of ZVI and poor crystallinity of D201-nZVI owing to the existence of a resin skeleton. However, the peak of $\mathrm{Fe}^{0}$ decreased with the corrosion process, indicating the oxidation and dissolution of ZVI. Different corrosion products in the four types of pre-corroded D201-nZVI were confirmed by XRD. For pre-corroded D3 and D4, the identified corrosion product was magnetite $\left(\mathrm{Fe}_{3} \mathrm{O}_{4}\right.$, JCPDS19-0629). Besides magnetite, hematite $\left(\mathrm{Fe}_{2} \mathrm{O}_{3}\right.$, JCPDS33-0664) was also identified in the pre-corroded D2 system. For pre-corroded $\mathrm{D} 1$, the dominant components were proved to be lepidocrocite $(\gamma-\mathrm{FeOOH}$, JCPDS44-1415) and goethite ( $\alpha$-FeOOH, JCPDS29-0713), which were most heavily oxidized in the $\mathrm{Cl}^{-}$system (Figure 2b) [1]. This implied that the particles had undergone severe oxidation during the pre-corrosion process. 

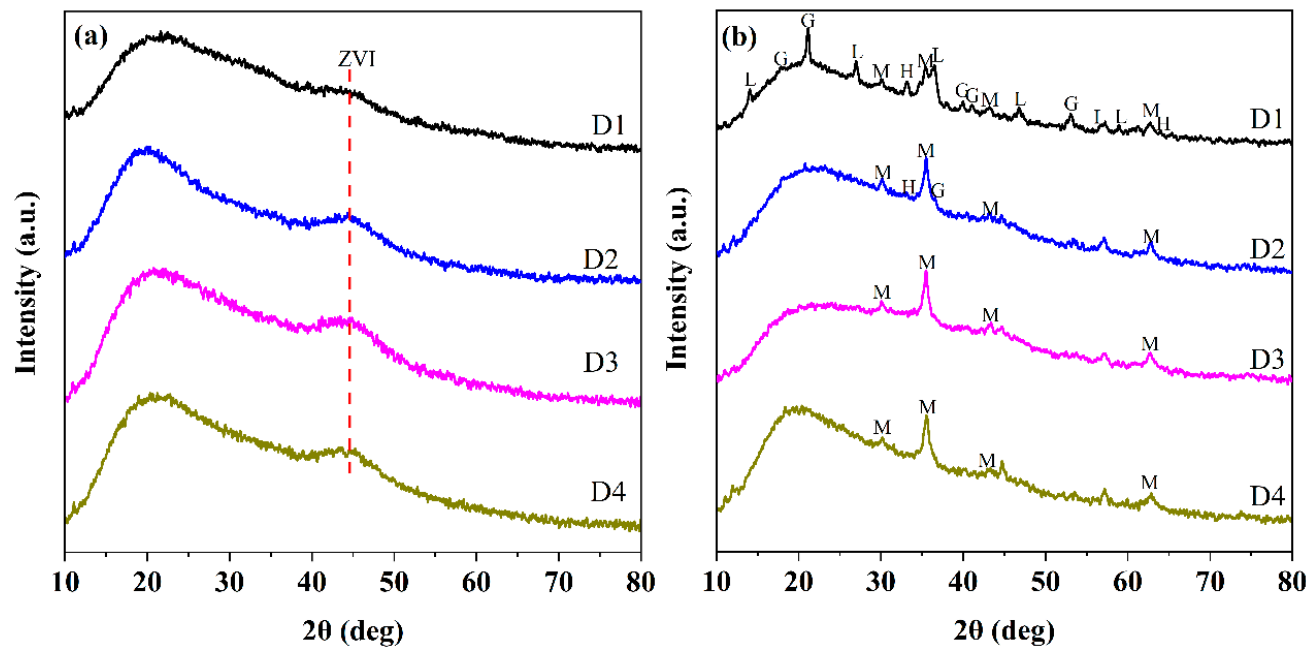

Figure 2. XRD patterns of fresh D201-ZVI (a) and D201-nZVI pre-corroded in the $\mathrm{Cl}^{-}$system (b) (M: magnetite $\left(\mathrm{Fe}_{3} \mathrm{O}_{4}\right)$; $\mathrm{H}$ : hematite $\left(\mathrm{Fe}_{2} \mathrm{O}_{3}\right)$; L: lepidocrocite $(\gamma-\mathrm{FeOOH})$; G: goethite $(\alpha-\mathrm{FeOOH})$.

\subsection{Cr(VI) Removal Kinetics of the D201-nZVI before and after Corrosion}

The removal properties of fresh and pre-corroded D201-nZVI toward Cr(VI) were systematically studied. Considering that the removal process involving nZVI contains an adsorption step resulting in an equilibrium effect, two kinetic models, pseudo-first-order and pseudo-second-order, were adopted to analyze the kinetics of the fresh and precorroded D201-nZVI. The non-linear forms of pseudo-first-order or pseudo-second-order kinetic equations could be followed as shown in Equations (1) and (2), respectively [27,28].

$$
\begin{gathered}
\mathrm{Q}_{\mathrm{t}}=\mathrm{Q}_{\mathrm{e}}\left(1-\mathrm{e}^{-\mathrm{k}_{1} \mathrm{t}}\right) \\
\mathrm{Q}_{\mathrm{t}}=\frac{\mathrm{k}_{2} \mathrm{Q}_{\mathrm{e}}^{2} \mathrm{t}}{1+\mathrm{k}_{2} \mathrm{Q}_{\mathrm{e}} \mathrm{t}}
\end{gathered}
$$

where $Q_{e}$ and $Q_{t}$ are the adsorption capacity of $\mathrm{Cr}(\mathrm{VI})(\mathrm{mg} / \mathrm{g})$ at the equilibrium and time $t$, respectively, and $k_{1}$ and $k_{2}$ are the pseudo-first-order and pseudo-second-order rate constants, respectively.

It can be seen from Figure 3 that the removal rates of $\mathrm{Cr}(\mathrm{VI})$ of all four types of fresh and pre-corroded D201-nZVI increased with the corrosion time within the first three hours, following the order of D4 > D3 > D2 > D1. However, after reaching the equilibrium, the removal efficiency of $\mathrm{Cr}(\mathrm{VI})$ followed the order of D1 $>$ D2 $>$ D4 $>$ D3. Although the removal rate of D1 was slow, the capacity at equilibrium was relatively high. D1 exhibited the best removal property before and after corrosion. In general, the adsorption capacity of pre-corroded D201-nZVI with same iron distribution was slightly larger than that of fresh D201-nZVI (Table 1). Figure 3 also showed the non-linear fitting plots of pseudo-first-order and pseudo-second-order kinetic models for $\mathrm{Cr}(\mathrm{VI})$ removal by fresh and pre-corroded D201-nZVI. The fitting parameters (Table 1) showed that two models could both generally fit the removal kinetic data $\left(R^{2}>0.94\right)$. The correlation coefficient $R^{2}$ of the pseudo-second-order kinetic model was higher than that of the pseudo-first-order kinetic model. However, the fitted adsorption capacity of $\mathrm{Cr}(\mathrm{VI})$ at the equilibrium derived from the pseudo-first-order model was closer to the experimental values. Liu [29] also reported similar results. This indicated that the $\mathrm{Cr}(\mathrm{VI})$ removal process was consistent with the pseudo-first-order kinetic model for this system. The rate constants of pseudo-firstorder $\left(\mathrm{k}_{1}\right)$ with D1 to D4 after aging $48 \mathrm{~h}$ were $8.01 \times 10^{-3}, 1.18 \times 10^{-2}, 1.75 \times 10^{-2}$, and $1.95 \times 10^{-2} \mathrm{~min}^{-1}$, respectively. After corrosion, the adsorption capacities were 134.61, $116.51,97.70$, and $104.21 \mathrm{mg} / \mathrm{g}$ for D1, D2, D3, and D4, respectively, indicating that the generation of corrosion products might be beneficial to increase the adsorption properties of pre-corroded D201-nZVI. 

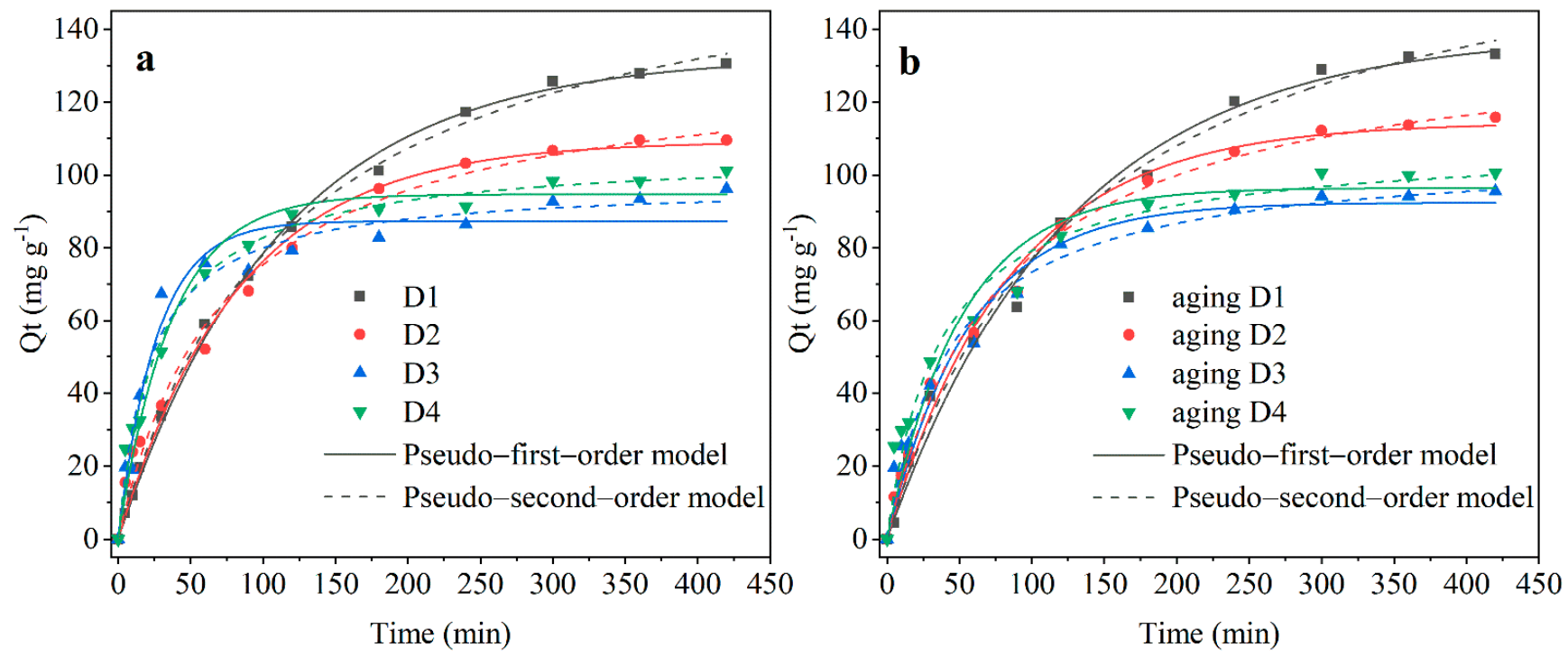

Figure 3. The kinetics of the pseudo-first-order and pseudo-second-order model for $\mathrm{Cr}(\mathrm{VI})$ removal by fresh D201-nZVI (a) and pre-corroded D201-nZVI after aging for $48 \mathrm{~h}$ (b).

Table 1. Kinetic parameters of the pseudo-first-order and pseudo-second-order model for $\mathrm{Cr}(\mathrm{VI})$ removal by fresh and pre-corroded D201-nZVI.

\begin{tabular}{|c|c|c|c|c|c|c|c|c|}
\hline \multirow[b]{2}{*}{$\begin{array}{c}\text { Corrosion } \\
\text { Time (h) }\end{array}$} & \multirow[b]{2}{*}{ Samples } & \multirow[b]{2}{*}{$\begin{array}{l}Q_{e}, \exp \\
(\mathrm{mg} / \mathrm{g})\end{array}$} & \multicolumn{3}{|c|}{ Pseudo-First-Order Kinetics } & \multicolumn{3}{|c|}{ Pseudo-Second-Order Kinetics } \\
\hline & & & $\mathbf{k}_{1}\left(\min ^{-1}\right)$ & $Q_{e}(\mathrm{mg} / \mathrm{g})$ & $\mathbf{R}^{2}$ & $\mathrm{k}_{2}\left(\mathrm{~g} \mathrm{mg}^{-1} \min ^{-1}\right)$ & $Q_{e}(m g / g)$ & $\mathbf{R}^{2}$ \\
\hline \multirow{4}{*}{0} & D1 & 130.58 & $8.95 \times 10^{-3}$ & 132.72 & 0.9978 & $5.85 \times 10^{-3}$ & 170.91 & 0.9988 \\
\hline & D2 & 109.52 & $1.20 \times 10^{-2}$ & 109.23 & 0.9817 & $7.59 \times 10^{-3}$ & 131.75 & 0.9880 \\
\hline & D3 & 96.18 & $3.76 \times 10^{-2}$ & 87.35 & 0.9610 & $1.02 \times 10^{-2}$ & 97.62 & 0.9723 \\
\hline & $\mathrm{D} 4$ & 101.10 & $2.73 \times 10^{-2}$ & 94.67 & 0.9745 & $9.43 \times 10^{-3}$ & 106.06 & 0.9899 \\
\hline \multirow{4}{*}{48} & D1 & 134.61 & $8.01 \times 10^{-3}$ & 138.77 & 0.9911 & $5.52 \times 10^{-3}$ & 181.04 & 0.9929 \\
\hline & $\mathrm{D} 2$ & 116.51 & $1.18 \times 10^{-2}$ & 114.33 & 0.9908 & $7.18 \times 10^{-3}$ & 139.29 & 0.9954 \\
\hline & D3 & 97.70 & $1.75 \times 10^{-2}$ & 92.42 & 0.9710 & $9.42 \times 10^{-3}$ & 106.16 & 0.9854 \\
\hline & D4 & 104.21 & $1.95 \times 10^{-2}$ & 96.45 & 0.9461 & $9.19 \times 10^{-3}$ & 108.82 & 0.9753 \\
\hline
\end{tabular}

\subsection{Effects of Different Corrosion Conditions on the Cr(VI) Removal}

\subsubsection{Corrosion Time}

Corrosion time had no significant effect on the $\mathrm{Cr}(\mathrm{VI})$ removal (Figure $4 \mathrm{a})$. In the corrosion process, the reduction of ZVI was weakened owing to the oxidation of ZVI in the water. Meanwhile, the adsorption of iron oxide/hydroxide was enhanced with the formation of corrosion products. The reduction of $\mathrm{Cr}(\mathrm{VI})$ with ZVI and coprecipitation of Fe(III) and $\mathrm{Cr}$ (III) could be expressed as shown in Equations (3) and (4) [30]. The effects of reduction and absorption were partly offset, so there was no obvious difference in $\mathrm{Cr}(\mathrm{VI})$ removal efficiency at the different corrosion times. The $\mathrm{Cr}(\mathrm{VI})$ removal efficiency by the four types of D201-nZVI followed the order of D1 > D2 > D3 > D4 at the same corrosion time (Figure 4a). This differed from the result obtained for the removal kinetics, which might have resulted from the insignificant differences between pre-corroded D3 and D4 on $\mathrm{Cr}(\mathrm{VI})$ removal.

$$
\begin{gathered}
\mathrm{CrO}_{4}^{2-}+\mathrm{Fe}^{0}+8 \mathrm{H}^{+} \rightarrow \mathrm{Fe}^{3+}+\mathrm{Cr}^{3+}+4 \mathrm{H}_{2} \mathrm{O} \\
(1-\mathrm{x}) \mathrm{Fe}^{3+}+(\mathrm{x}) \mathrm{Cr}^{3+}+2 \mathrm{H}_{2} \mathrm{O} \rightarrow \mathrm{Fe}_{(1-\mathrm{x})} \mathrm{Cr}_{\mathrm{x}} \mathrm{OOH} \downarrow+3 \mathrm{H}^{+}
\end{gathered}
$$




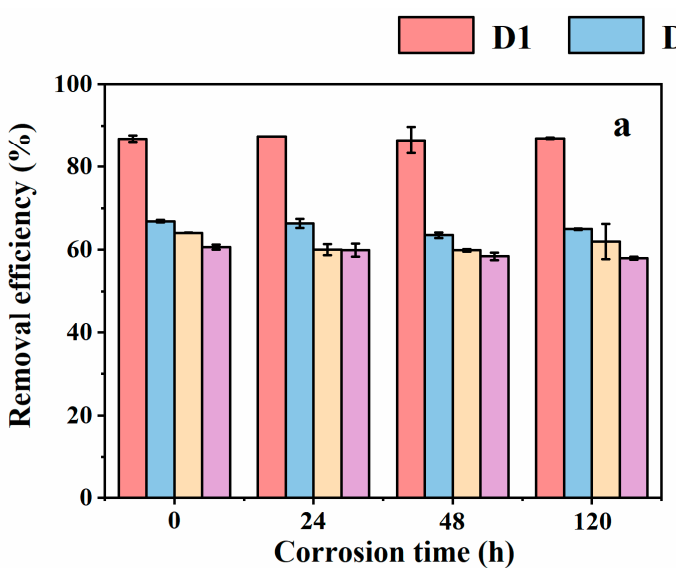

D2 $\square$ D3 $\square$ D4
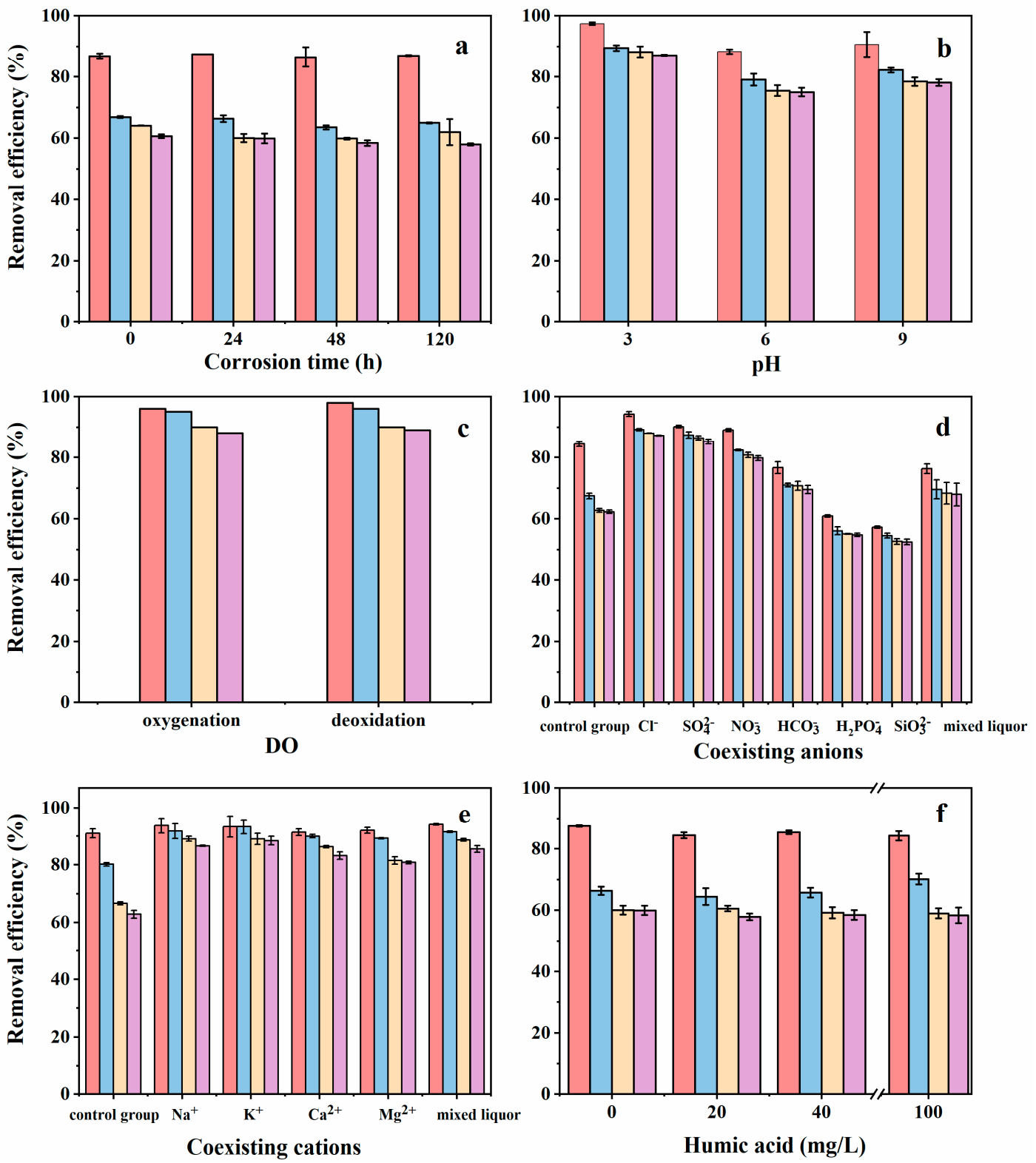

Figure 4. Effect of the corrosion time (a), initial $\mathrm{pH}(\mathrm{b})$, dissolved oxygen (c), coexisting anions (d), coexisting cations (e), and humic acid (f) on Cr(VI) removal by pre-corroded D201-nZVI.

Four types of D201-nZVI had almost the same iron content. However, nZVI in the D1 sample was primarily distributed on the outside of the resin, meaning that more iron oxide might be produced. The intensity of the iron oxide peaks in the pre-corroded D1 was stronger than that of pre-corroded D2, D3, and D4, confirming that the adsorption of iron oxide in the pre-corroded D1 system was better. This might explain why the removal efficiency followed the order of D1 > D2 > D3 > D4 (Figure 4a).

\subsubsection{Initial $\mathrm{pH}$}

As shown in Figure $4 \mathrm{~b}$, the removal efficiency increased in the order of $\mathrm{pH} 3>\mathrm{pH} 9>\mathrm{pH} 6$. Previous studies have demonstrated that acid could dissolve the oxides on the surface of ZVI nanoparticles under acidic conditions, slowing down the corrosion of ZVI and maintaining a fresh $\mathrm{Fe}^{0}$ surface [31], which might be beneficial to improve the reduction of pre-corroded D201-nZVI to promote the $\mathrm{Cr}(\mathrm{VI})$ removal. This might explain why precorroded D201-nZVI exhibited the best removal efficiency under acidic conditions. Under 
alkaline conditions, ZVI could transform into oxide or hydroxide to promote the production of $\gamma$-FeOOH. Pre-corroded ZVI generally had a stratified structure including three layers: inner core of $\mathrm{Fe}^{0}$, outer shell of $\gamma-\mathrm{FeOOH}$, and middle layer of $\mathrm{Fe}_{3} \mathrm{O}_{4} / \mathrm{FeO}$. The $\mathrm{Fe}_{3} \mathrm{O}_{4}$ in the middle layer tend to gradually oxidize to $\mathrm{Fe}(\mathrm{OH})_{3}$ or $\gamma$-FeOOH in the presence of $\mathrm{O}_{2}$, as shown in Equations (5) and (6) [32]. $\gamma$-FeOOH showed a strong absorption of $\mathrm{Cr}(\mathrm{VI})$, which might be the reason that $\mathrm{Cr}(\mathrm{VI})$ removal by pre-corroded D201-nZVI was better in alkaline solutions. The $\mathrm{Cr}(\mathrm{VI})$ removal followed the order of D1 > D2 > D3 > D4 at the same initial $\mathrm{pH}$, which was consistent with the above-mentioned conclusion (Figure $4 \mathrm{~b}$ ).

$$
\begin{gathered}
4 \mathrm{Fe}_{3} \mathrm{O}_{4}+\mathrm{O}_{2}+18 \mathrm{H}_{2} \mathrm{O} \rightarrow 12 \mathrm{Fe}(\mathrm{OH})_{3} \\
4 \mathrm{Fe}_{3} \mathrm{O}_{4}+\mathrm{O}_{2}+6 \mathrm{H}_{2} \mathrm{O} \rightarrow 12 \gamma-\mathrm{FeOOH}
\end{gathered}
$$

\subsubsection{Dissolved Oxygen}

There was insignificant difference in $\mathrm{Cr}(\mathrm{VI})$ removal by pre-corroded D201-nZVI in aerobic and anaerobic systems (Figure 4c), which confirmed that DO had little effect on the $\mathrm{Cr}(\mathrm{VI})$ removal. The $\mathrm{Cr}(\mathrm{VI})$ removal involved adsorption and reduction. High DO levels prompted the formation of iron oxide or hydroxide on the surface of pre-corroded D201-nZVI, which weakened the electron transport from $\mathrm{Fe}^{0}$ to $\mathrm{Cr}(\mathrm{VI})$. Oppositely, low DO levels prompted the reduction of pre-corroded D201-nZVI, which weakened the formation of iron oxide or hydroxide. The corrosion of ZVI has been well documented and the corrosion process is shown in Equations (7) and (9) [33]. These effects were partly offset, so there was no obvious difference in $\mathrm{Cr}(\mathrm{VI})$ removal efficiency in aerobic and anaerobic systems. The removal efficiency of Cr(VI) by pre-corroded D201-nZVI followed the order of D1 > D2 > D3 > D4 at the same DO concentration (Figure 4c).

$$
\begin{gathered}
2 \mathrm{Fe}^{0}+2 \mathrm{H}_{2} \mathrm{O}+\mathrm{O}_{2} \rightarrow 2 \mathrm{Fe}^{2+}+4 \mathrm{OH}^{-} \\
4 \mathrm{Fe}(\mathrm{OH})_{2}+\mathrm{O}_{2}+2 \mathrm{H}_{2} \mathrm{O} \rightarrow 4 \mathrm{Fe}(\mathrm{OH})_{3} \\
4 \mathrm{Fe}^{2+}+\mathrm{O}_{2}+4 \mathrm{H}^{+} \rightarrow 4 \mathrm{Fe}^{3+}+2 \mathrm{H}_{2} \mathrm{O}
\end{gathered}
$$

\subsubsection{Coexisting Ions}

Previous studies demonstrated that coexisting ions were adsorbed on the ZVI surface and had an effect on the corrosion evolution through multiple mechanisms [32]. In this study, we explored the effects of coexisting ions on the $\mathrm{Cr}(\mathrm{VI})$ removal by pre-corroded D201nZVI. Generally, the effect of coexisting anions of pre-corroded D201-nZVI on Cr(VI) removal followed the order of $\mathrm{Cl}^{-}>\mathrm{SO}_{4}{ }^{2-}>\mathrm{NO}_{3}{ }^{-}>\mathrm{HCO}_{3}{ }^{-}>\mathrm{H}_{2} \mathrm{O}$ (control) $>\mathrm{H}_{2} \mathrm{PO}_{4}{ }^{-}>\mathrm{SiO}_{3}{ }^{2-}$ in the same system (Figure $4 \mathrm{~d}$ ). To be simplified, the roles of six types of coexisting anions could be divided into two categories based on the positive or negative contribution to the reaction process.

Compared with aqueous solution, the effective peak intensity or number of corrosion products in the $\mathrm{Cl}^{-}, \mathrm{SO}_{4}{ }^{2-}, \mathrm{NO}_{3}{ }^{-}$, and $\mathrm{HCO}_{3}{ }^{-}$system increased (Figure 5), indicating that the presence of $\mathrm{Cl}^{-}, \mathrm{SO}_{4}{ }^{2-}, \mathrm{NO}_{3}{ }^{-}$, and $\mathrm{HCO}_{3}{ }^{-}$in the corrosion process promoted the generation of iron oxide to improve the $\mathrm{Cr}(\mathrm{VI})$ removal by pre-corroded D201-nZVI. The presence of iron oxide might be beneficial to increase the adsorption properties of pre-corroded D201-nZVI. In contrast, a lower corrosion degree was observed in the pre-corroded D201-nZVI from $\mathrm{H}_{2} \mathrm{PO}_{4}{ }^{-}$and $\mathrm{SiO}_{3}{ }^{2-}$ solution, which was consistent with the results shown in Figure $4 \mathrm{~d}$. For instance, the effective peak intensity of iron oxide of D201-nZVI in the $\mathrm{Cl}^{-}, \mathrm{NO}_{3}{ }^{-}$, and $\mathrm{SO}_{4}{ }^{2-}$ system was higher than that of D201-nZVI in the $\mathrm{HCO}_{3}{ }^{-}$system. The removal efficiency of D201-nZVI in the $\mathrm{HCO}_{3}{ }^{-}$system was the lowest among the four types of anions. Generally, it was considered that the corrosion of ZVI occurred through the electrochemical process, with $\mathrm{Fe}^{0}$ dissolution as the anodic process and $\mathrm{H}_{2}$ evolution $/ \mathrm{O}_{2}$ adsorption as the cathodic process. $\mathrm{H}_{2}$ evolution corrosion mainly occurred at $\mathrm{pH}<4$, while $\mathrm{O}_{2}$ adsorption mainly occurred when $\mathrm{pH}$ ranged from 4 to 10 [32]. Thus, it was reasonable that the iron corrosion was dominated 
by $\mathrm{O}_{2}$ adsorption corrosion in our study because the $\mathrm{pHs}$ of all the employed salt solutions were in the range of $4-10$.

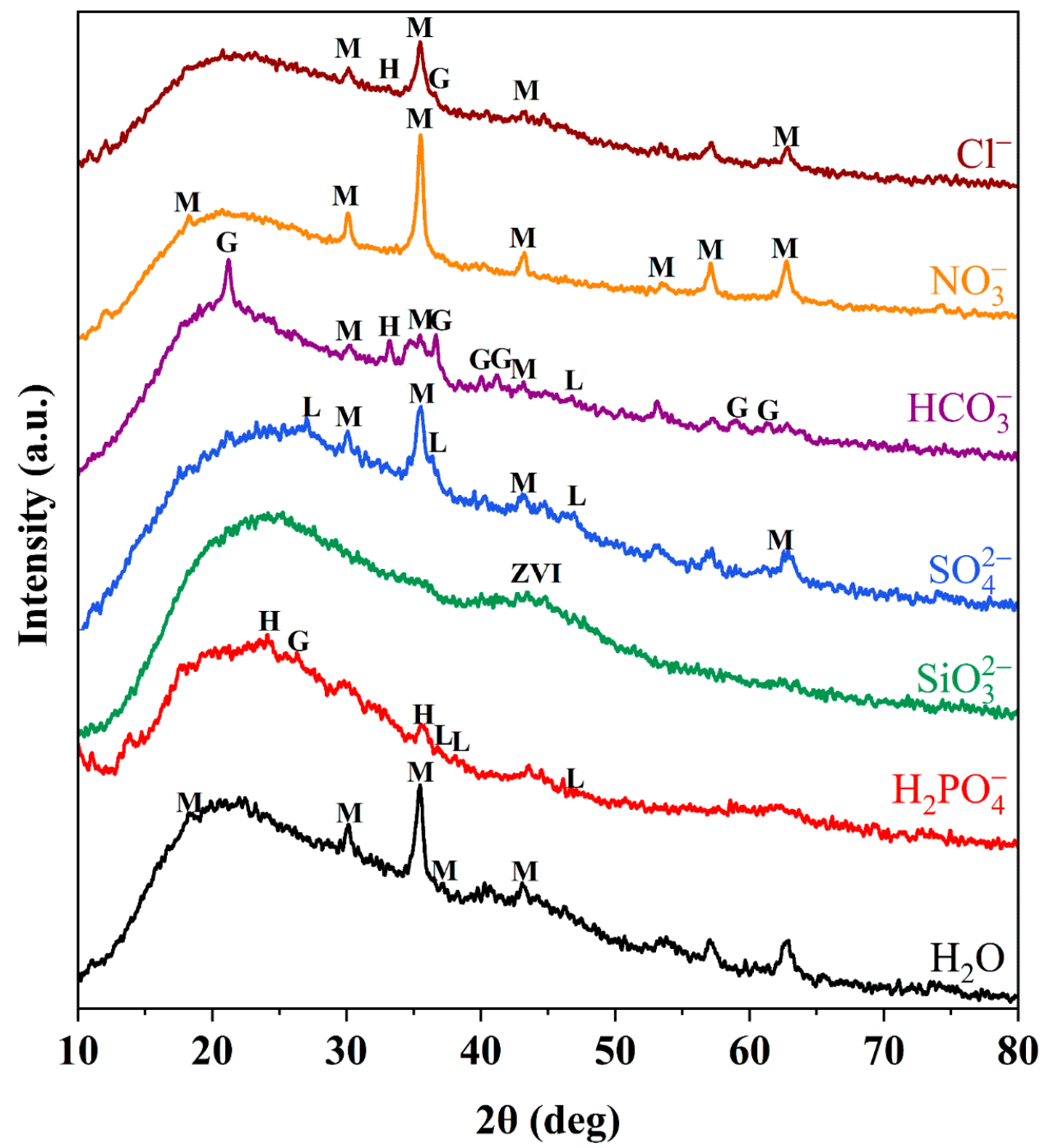

Figure 5. XRD patterns of D201-nZVI pre-corroded in the different system (M: magnetite $\left(\mathrm{Fe}_{3} \mathrm{O}_{4}\right)$; $\mathrm{H}$ : hematite $\left(\mathrm{Fe}_{2} \mathrm{O}_{3}\right)$; L: lepidocrocite $(\gamma-\mathrm{FeOOH})$; G: goethite $\left.(\alpha-\mathrm{FeOOH})\right)$.

$\mathrm{Cl}^{-}$could enter the center of ZVI and formed stable coordination complexes, which facilitated the formation of new reactive sites on the surface of pre-corroded D201-nZVI to promote the $\mathrm{Cr}(\mathrm{VI})$ removal [33]. Previous studies confirmed that $\mathrm{SO}_{4}{ }^{2-}$ could be incorporated into the crystal structure and the inner iron oxide/hydroxide double layer might promote the ZVI corrosion [32]. Green rust might be produced on the D201-nZVI surface during the corrosion process, which was conducive to the reduction of $\mathrm{Cr}(\mathrm{VI})$ removal by green $\mathrm{Fe}(\mathrm{II})$ rust [34]. Moreover, it has been reported that $\mathrm{Fe}_{3} \mathrm{O}_{4}$, the product of the $\mathrm{NO}_{3}{ }^{-}$ and $\mathrm{Fe}^{0}$, was the reason $\mathrm{NO}_{3}{ }^{-}$promoted the $\mathrm{Cr}(\mathrm{VI})$ removal by pre-corroded D201-nZVI. $\mathrm{Fe}_{3} \mathrm{O}_{4}$ blocked the accumulation of corrosion products on the surface of pre-corroded D201-nZVI, and promoted the electron conduction, which contributed to the removal of $\mathrm{Cr}(\mathrm{VI})$ [35]. In addition, $\mathrm{HCO}_{3}{ }^{-}$could have the process of ionization and hydrolysis in the solution simultaneously, preventing the rapid change in $\mathrm{pH}$ in the corrosion system. It could also produce a small quantity of $\mathrm{H}^{+}$, in turn slowing down the production of iron oxide/hydroxide on the pre-corroded D201-nZVI surface and promoting the $\mathrm{Cr}(\mathrm{VI})$ removal [31]. However, the generated $\mathrm{Fe}^{2+}$ in the presence of $\mathrm{HCO}_{3}{ }^{-}$might react with $\mathrm{HCO}_{3}{ }^{-}$to form iron carbonate $\mathrm{FeCO}_{3}$ on the pre-corroded D201-ZVI surface, which slowed 
down the electron transfer, reducing the $\mathrm{Cr}(\mathrm{VI})$ removal [36]. This might explain why the efficiency in the $\mathrm{HCO}_{3}{ }^{-}$system was smaller than in the $\mathrm{Cl}^{-}, \mathrm{SO}_{4}{ }^{2-}$, and $\mathrm{NO}_{3}{ }^{-}$system.

In contrast, the presence of $\mathrm{H}_{2} \mathrm{PO}_{4}{ }^{-}$and $\mathrm{SiO}_{3}{ }^{2-}$ in the corrosion process inhibited the $\mathrm{Cr}(\mathrm{VI})$ removal by pre-corroded D201-nZVI. Phosphate reacted with $\mathrm{Fe}(\mathrm{II})$ to produce $\mathrm{Fe}_{3}\left(\mathrm{PO}_{4}\right)_{2} \cdot 8 \mathrm{H}_{2} \mathrm{O}$ precipitate coating on the D201-nZVI surface in the $\mathrm{H}_{2} \mathrm{PO}_{4}{ }^{-}$system and its deposition might inhibit the further corrosion of ZVI. As a corrosion inhibitor, $\mathrm{SiO}_{3}{ }^{2-}$ could be attributed to its polymerization and coating effects in this study. During the corrosion process, silicate could be adsorbed on the corrosion products as a barrier and, gradually, silica polymer or amorphous solid phase was formed on the surface of D201-ZVI to inhibit corrosion [32], which might inhibit the removal efficiency of $\mathrm{Cr}(\mathrm{VI})$ by pre-corroded D201-nZVI.

Compared with aqueous solution, almost all cations in the corrosion process significantly contributed to the $\mathrm{Cr}(\mathrm{VI})$ removal by pre-corroded D201-nZVI. However, it was known that $\mathrm{Cl}^{-}$strongly promoted the $\mathrm{Cr}(\mathrm{VI})$ removal, indicating the effect of $\mathrm{Cl}^{-}$on the removal must be considered in the corrosion. Therefore, $\mathrm{Na}^{+}$and $\mathrm{K}^{+}$had insignificant effects on the $\mathrm{Cr}(\mathrm{VI})$ removal in the corrosion because of their solubilities. Compared with univalent cations, the presence of bivalent cations inhibited the $\mathrm{Cr}(\mathrm{VI})$ removal by pre-corroded D201-nZVI (Figure 4e). Previous studies indicated that $\mathrm{Ca}^{2+}$ might occupy the adsorption sites on the surface of D201-nZVI [37,38]. Similarly, a magnesium oxidehydroxide passivation layer formed on the surface of D201-nZVI in the $\mathrm{Mg}^{2+}$ system, which reduced the number of reactive sites and had a negative effect on the $\mathrm{Cr}(\mathrm{VI})$ removal [37]. The $\mathrm{Cr}(\mathrm{VI})$ removal by the four types of pre-corroded D201-nZVI under the same ion conditions in the corrosion process. The removal efficiency followed the order of D1 $>$ D2 > D3 > D4 (Figure 4d,e).

\subsubsection{Humic Acid}

Natural organic matter, typically humus, is a constituent of water and soil [37]. Based on its solubility in acidic or alkaline solutions, humus, a brown amorphous polymer, can be divided into humic acid (HA, insoluble in acid), fulvic acid (FA, soluble in both acidic and alkaline solutions), and humin (insoluble in both acidic and alkaline solutions) [39]. The presence of HA in the corrosion slightly inhibited the $\mathrm{Cr}(\mathrm{VI})$ removal by pre-corroded D201-ZVI (Figure 4f). When other reductants were absent, HA had a weak reductivity. The occupation of the reactive sites by HA in the corrosion would inhibit the removal by pre-corroded D201-nZVI. Meanwhile, HA tend to form ZVI-HA complexes in the corrosion, which also inhibited the $\mathrm{Cr}(\mathrm{VI})$ removal $[37,40]$. The $\mathrm{Cr}(\mathrm{VI})$ removal by the four types of pre-corroded D201-ZVI still followed the order of D1 > D2 > D3 > D4 under the same HA concentration (Figure 4f).

\subsection{Cr(VI) Removal Mechanism of Pre-Corroded D201-nZVI}

The mechanism of $\mathrm{Cr}(\mathrm{VI})$ removal by pre-corroded D201-nZVI was explored based on SEM-EDS and XPS analyses. The SEM-EDS spectra of elemental Cr mapping in the cross section of pre-corroded D1-D4 after reaction with $\mathrm{Cr}(\mathrm{VI})$ indicated that the $\mathrm{Cr}$ element was well dispersed (Figure 6) and was different from the Fe element on the surface of pre-corroded D201-nZVI (Figure 1). It could be inferred that $\mathrm{Cr}(\mathrm{VI})$ removal by precorroded D201-nZVI included the reduction of nZVI and adsorption of resin through the ion exchange. ZVI occupied the reactive sites of the internal resin with the increase in the uniformity of the iron distribution on the resin, which might weaken the adsorption of resin. Meanwhile, the improvement in ZVI uniformity on the resin promoted contact with $\mathrm{ZVI}$ and $\mathrm{Cr}(\mathrm{VI})$, which might strengthen the reduction of $\mathrm{ZVI}$. 

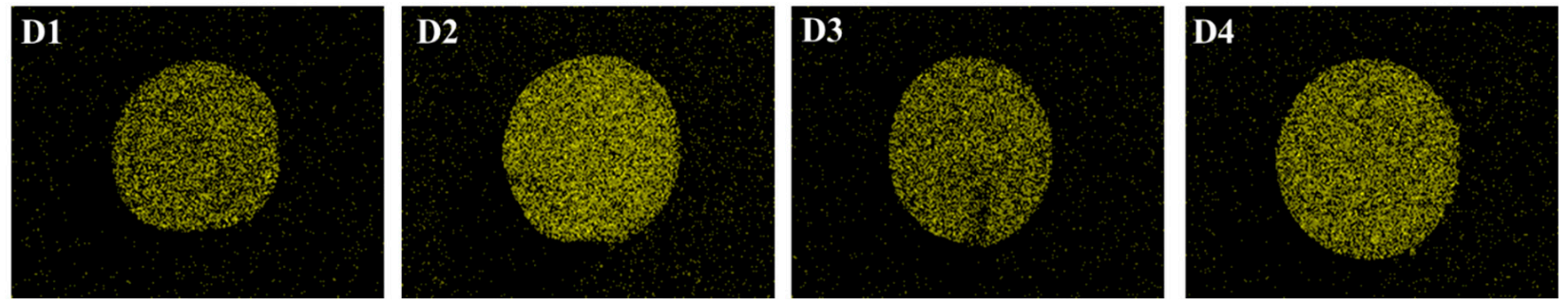

Figure 6. SEM-EDS spectra of elemental Cr mapping in the cross section of pre-corroded D1-D4 after reaction with $\mathrm{Cr}(\mathrm{VI})$.

XPS analysis was performed to further investigate the chemical compositions and the oxidation states of $\mathrm{Cr}$ and $\mathrm{Fe}$ on the surface of pre-corroded D1-D4 after reaction with $\mathrm{Cr}(\mathrm{VI})$. There were elements $\mathrm{Fe}, \mathrm{C}, \mathrm{O}$, and $\mathrm{N}$ that could be detected before the reaction with $\mathrm{Cr}(\mathrm{VI})$ on the survey scan of the XPS spectra (Figure S2a). However, the new peak appeared at 577 and $586 \mathrm{eV}$, corresponding to the element $\mathrm{Cr}$, after reaction with $\mathrm{Cr}(\mathrm{VI})$, which indicated that $\mathrm{Cr}$ was successfully immobilized on the surface of the pre-corroded D201-nZVI (Figure S2b). Moreover, the high-resolution XPS spectra of Fe 2p and Cr 2p regions are shown in Figure 7. A survey spectrum of the Fe 2p levels after reaction with $\mathrm{Cr}(\mathrm{VI})$ (Figure 7a) showed photoelectron peaks at 724.20 and $725.50 \mathrm{eV}$ corresponding to the binding energy of $\mathrm{Fe} 2 \mathrm{p} 1 / 2$, while the binding energies at 710.30 and $712.30 \mathrm{eV}$ in the high-resolution $\mathrm{Fe} 2 \mathrm{p} 3 / 2$ spectra represented $\mathrm{Fe}^{2+}$ and $\mathrm{Fe}^{3+}$ in $\mathrm{FeCr}_{2} \mathrm{O}_{4}$, and $\mathrm{Fe}_{3} \mathrm{O}_{4}$, respectively [41], which also implied that ZVI was present on the surface of D201 and was covered by a layer of iron oxides.

Furthermore, the reduction of $\mathrm{Cr}(\mathrm{VI})$ was apparent from the Cr 2p XPS spectra for D201-nZVI after reaction with $\mathrm{Cr}(\mathrm{VI})$ (Figure $7 \mathrm{~b}$ ). The $\mathrm{Cr} 2 \mathrm{p} 3 / 2$ peaks at 576.80 and $579.00 \mathrm{eV}$ correspond to $\mathrm{Cr}(\mathrm{OH})_{3}$ and $\mathrm{K}_{2} \mathrm{CrO}_{4}$, respectively [42], which suggested that both adsorption and redox reaction contributed to the removal of $\mathrm{Cr}(\mathrm{VI})$ and coprecipitates were formed during $\mathrm{Cr}(\mathrm{VI})$ adsorption and reduction. After reaction with $\mathrm{Cr}(\mathrm{VI}), 37.63 \%$, $35.23 \%, 33.84 \%$, and $27.20 \%$ of D201-nZVI surface from D1 to D4 remained as $\mathrm{Cr}(\mathrm{VI})$, while $62.37 \%, 64.77 \%, 66.16 \%$, and $72.80 \%$ was converted to Cr(III) (Figure $8 \mathrm{~b}$ and Table S2). Most of the chromium adsorbed on the surface of D201 was reduced to $\mathrm{Cr}(\mathrm{III})$, with only less remaining as the $\mathrm{Cr}(\mathrm{VI})$ form. These results also revealed that both adsorption and redox reaction contributed to the removal of $\mathrm{Cr}(\mathrm{VI})$ from aqueous solution. Meanwhile, the peak areas corresponding to the Fe(II) from D1 to D4 were $44.53 \%, 48.73 \%, 52.33 \%$, and $54.06 \%$, respectively (Figure $8 \mathrm{a}$ and Table S1), indicating that the ZVI acted as an electron donor and contributed to the reduction of $\mathrm{Cr}(\mathrm{VI})$ to $\mathrm{Cr}(\mathrm{III})$ on the surface of D201.

XPS results confirmed the combined effects of adsorption and reduction achieved by modification of D201 with ZVI to improve Cr(VI) removal ability of D201-nZVI, and the corresponding mechanism might involve the generation of nascent $\mathrm{Fe}(\mathrm{II})$ and electron transfer from the corrosion evolution of nZVI. The proportion of $\mathrm{Cr}$ (III) gradually increased with the increase in the uniformity of the iron distribution on the resin, indicating that the increase in iron distribution uniformity was favorable for reduction of pre-corroded D201-nZVI. Moreover, the ratio of Cr(III) on the pre-corroded D201-nZVI surface was much higher than that of $\mathrm{Cr}(\mathrm{VI})$, which confirmed that the reduction was the main removal mechanism of pre-corroded D201-nZVI. The surface-bound Fe(II) on the surface of precorroded D201-nZVI and the corrosion products might increase the surface positive charge in favor of adsorption and reduction of $\mathrm{Cr}(\mathrm{VI})$. Generally, the $\mathrm{Cr}(\mathrm{VI})$ removal mechanism by pre-corroded D201-nZVI included the direct/indirect reduction of nZVI, adsorption of iron oxide/hydroxide, and adsorption of D201 resin. 
(a)
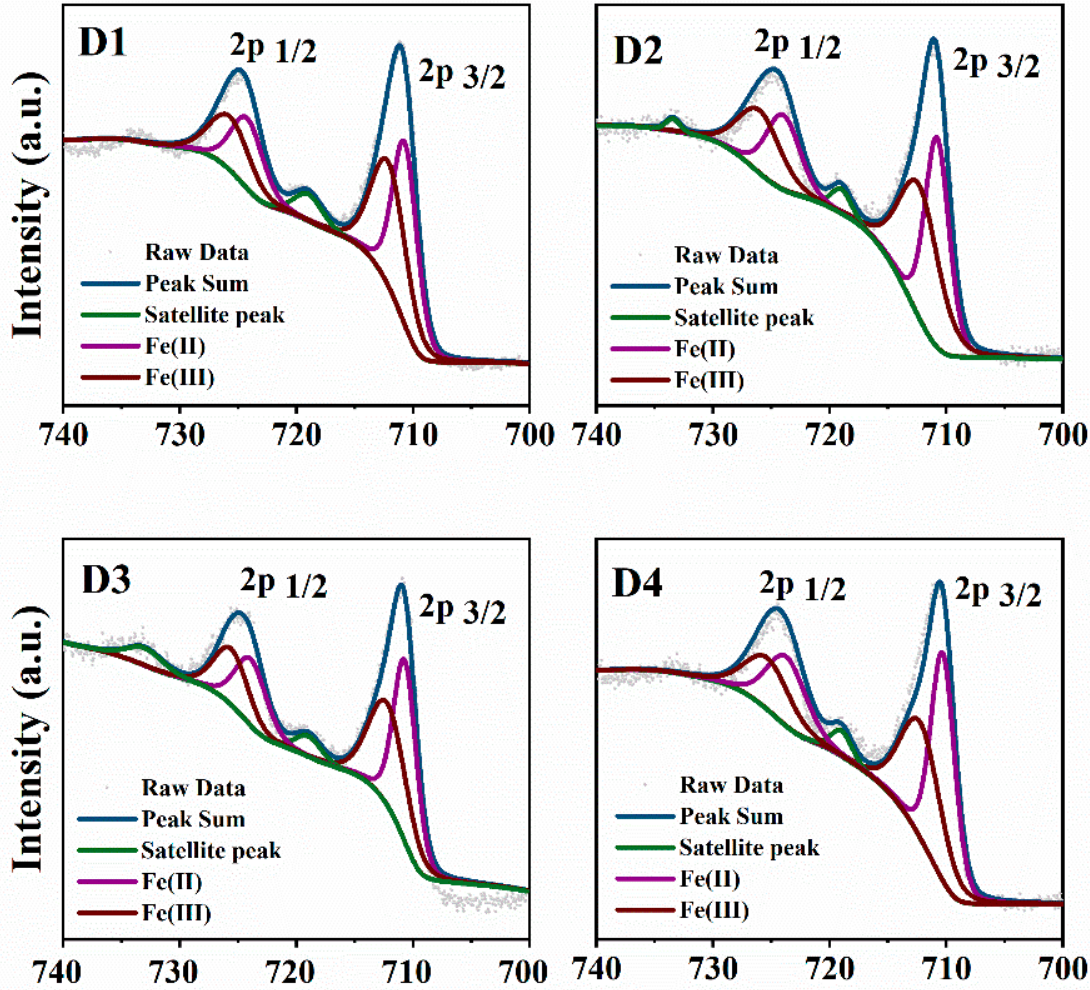

B.E. (eV)

$$
\text { B.E. }(\mathrm{eV})
$$
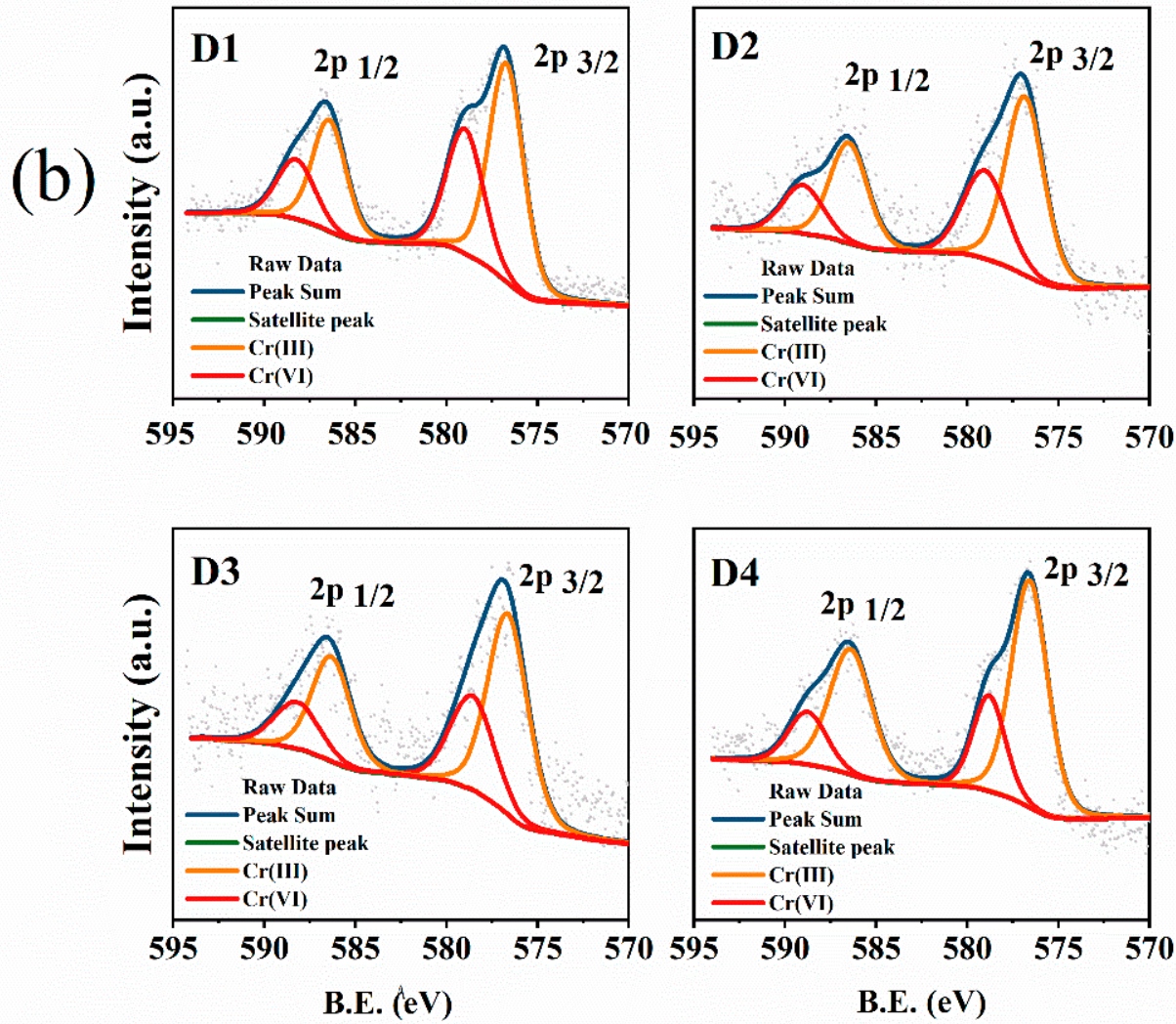

Figure 7. Fe2p (a) and Cr2p (b) high-resolution XPS spectra of pre-corroded D1-D4 after reaction with $\mathrm{Cr}(\mathrm{VI})$. 


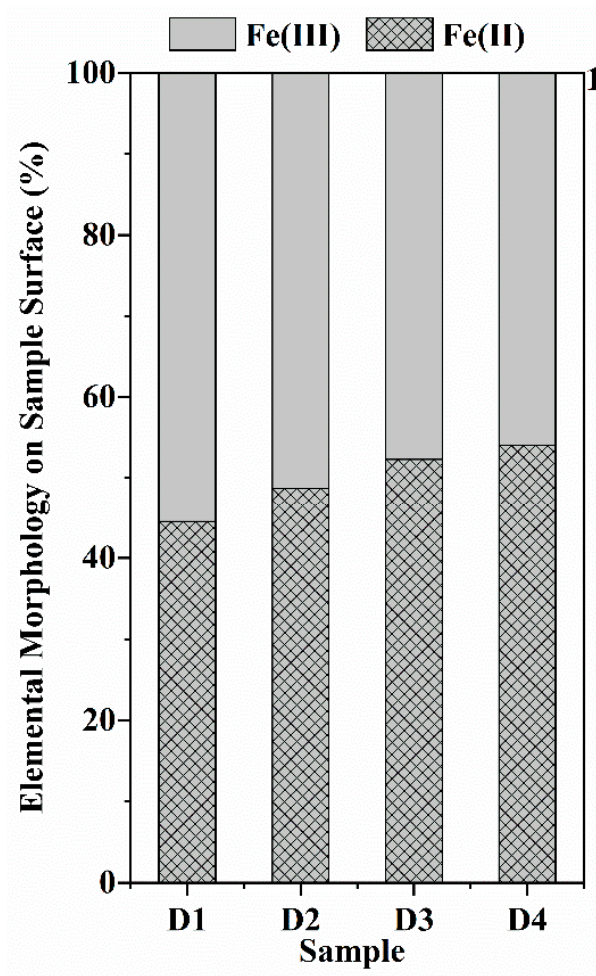

(a)

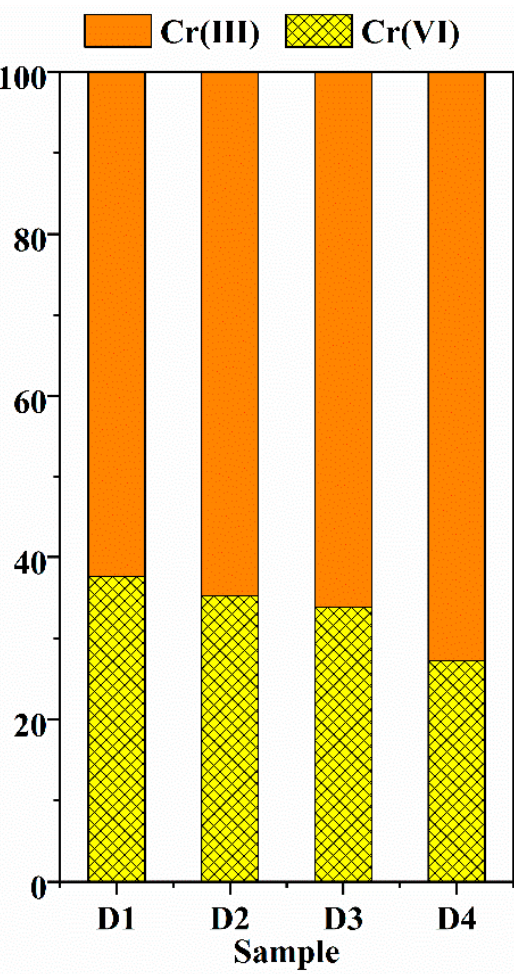

(b)

Figure 8. Oxidation states of $\mathrm{Fe}(\mathbf{a})$ and $\mathrm{Cr}(\mathbf{b})$ immobilized onto pre-corroded D1-D4 after reaction with $\mathrm{Cr}(\mathrm{VI})$.

\section{Conclusions}

In this study, the effect of spatial distribution of nZVI on the corrosion behavior of D201-nZVI and the Cr(VI) removal by the corresponding pre-corroded D201-nZVI were systematically investigated. The $\mathrm{Cr}(\mathrm{VI})$ removal efficiency by the four types of precorroded D201-nZVI followed the order of D1 > D2 > D3 > D4 at the same corrosion condition. Acidic or alkaline conditions and all coexisting ions except $\mathrm{SiO}_{3}{ }^{2-}$ and $\mathrm{H}_{2} \mathrm{PO}_{4}{ }^{-}$ enhanced the corrosion of nZVI to different extents during the corrosion process. The effect of coexisting anions of pre-corroded D201-nZVI on $\mathrm{Cr}(\mathrm{VI})$ removal followed the order of $\mathrm{Cl}^{-}>\mathrm{SO}_{4}{ }^{2-}>\mathrm{NO}_{3}{ }^{-}>\mathrm{HCO}_{3}{ }^{-}>\mathrm{H}_{2} \mathrm{O}>\mathrm{H}_{2} \mathrm{PO}_{4}{ }^{-}>\mathrm{SiO}_{3}{ }^{2-}$ in the same system. Meanwhile, humic acid in the corrosion system slightly decelerated $\mathrm{Cr}(\mathrm{VI})$ removal. The corrosion products derived from nZVI, including magnetite, hematite, lepidocrocite, and goethite, were identified by XRD. The dominant corrosion products were found to be highly dependent on the type of coexisting ions, and the roles of different coexisting anions on nZVI corrosion were also elucidated. The distributions of $\mathrm{Fe}$ and $\mathrm{Cr}$ oxidation states immobilized onto pre-corroded D201-nZVI were revealed by XPS analysis, and we found that the nZVI acted as an electron donor and contributed to the reduction of $\mathrm{Cr}(\mathrm{VI})$ to $\mathrm{Cr}$ (III) on the surface of D201, and the increase in iron distribution uniformity was favorable for the reduction of pre-corroded D201-nZVI. The mechanisms of $\mathrm{Cr}(\mathrm{VI})$ removal by pre-corroded D201-nZVI were proved to be a comprehensive process involving the direct/indirect reduction of $\mathrm{nZVI}$, adsorption of iron oxide/hydroxide, and adsorption of D201 resin, and reduction was the main removal mechanism of pre-corroded D201-nZVI. This study provides insight into the selection of nZVI composites with different spatial distribution of pre-corroded nZVI under different coexisting solutions for practical water remediation and promotes the understanding of the fate of $\mathrm{ZVI}-\mathrm{Cr}(\mathrm{VI})$ reaction products in the natural environment. 
Supplementary Materials: The supplementary materials can be download at the following link: https:/ / www.mdpi.com/article/10.3390/nano12030494/s1. Table S1. The properties of four types of fresh D201-nZVI. Table S2. Oxidation states proportion of Fe and Cr immobilized onto pre-corroded D201-nZVI surface after reaction with $\mathrm{Cr}(\mathrm{VI})$. Figure S1. Effect of the $\mathrm{Cl}^{-}$concentration on $\mathrm{Cr}(\mathrm{VI})$ removal by pre-corroded D201-nZVI. Figure S2. XPS spectra of pre-corroded D201-nZVI (a) before (b) after reaction with $\mathrm{Cr}(\mathrm{VI})$.

Author Contributions: Conceptualization, Y.L., S.H., Q.D.; methodology, S.H., Y.S.; software, Y.S.; validation, X.Z., S.L.; formal analysis, Y.L., S.H., Y.S.; investigation, Y.L., S.H.; resources, Y.L., Q.D.; data curation, Y.L., X.Z.; writing - original draft preparation, Y.L., S.H.; writing-review and editing, Y.S., Q.D.; visualization, Y.L., Y.S.; supervision, Q.D.; project administration, Q.D.; funding acquisition, Q.D. All authors have read and agreed to the published version of the manuscript.

Funding: This study was supported by the National Natural Science Foundation of China (No. 21707166), the Open Foundation of State Key Laboratory of Pollution Control and Resource Reuse (PCRRF20044, Nanjing University), and the Fundamental Research Funds for the Central Universities (No. 2632019ZD13)

Data Availability Statement: Data can be available upon request from the authors.

Acknowledgments: We would like to thank Jiafen Ding for assistance in the experiment.

Conflicts of Interest: The authors declare no conflict of interest.

\section{References}

1. Qiao, J.; Liu, Y.; Yang, H.; Guan, X.; Sun, Y. Remediation of arsenic contaminated soil by sulfidated zero-valent iron. Front. Environ. Sci. Eng. 2021, 15, 1-11. [CrossRef]

2. Stefaniuk, M.; Oleszczuk, P.; Ok, Y.S. Review on nano zerovalent iron (nZVI): From synthesis to environmental applications Chem. Eng. J. 2016, 287, 618-632. [CrossRef]

3. Bezza, F.A.; Chirwa, E. Removal of Phosphate from Contaminated Water Using activated carbon supported Nanoscale Zero-Valent Iron (nZVI) Particles. Chem. Eng. Trans. 2021, 84, 1-6.

4. Soliemanzadeh, A.; Fekri, M. Synthesis of clay-supported nanoscale zero-valent iron using green tea extract for the removal of phosphorus from aqueous solutions. Chin. J. Chem. Eng. 2017, 7, 100-106. [CrossRef]

5. Wu, Y.; Yao, H.; Khan, S.; Hu, S.; Wang, L. Characteristics and Mechanisms of Kaolinite-Supported Zero-Valent Iron/ $\mathrm{H}_{2} \mathrm{O}_{2}$ System for Nitrobenzene Degradation. Clean 2017, 45, 1600826.1-1600826.9.

6. Xie, Y.; Yi, Y.; Qin, Y.; Wang, L.; Liu, G.; Wu, Y.; Diao, Z.; Zhou, T.; Xu, M. Perchlorate degradation in aqueous solution using chitosan-stabilized zero-valent iron nanoparticles. Sep. Purif. Technol. 2016, 171, 164-173. [CrossRef]

7. Liu, F.; Shan, C.; Zhang, X.; Zhang, Y.; Zhang, W.; Pan, B. Enhanced removal of EDTA-chelated Cu(II) by polymeric anionexchanger supported nanoscale zero-valent iron. J. Hazard. Mater. 2017, 321, 290-298. [CrossRef]

8. Santos-Juanes, L.; Einschlag, F.S.G.; Amat, A.M.; Arques, A. Combining ZVI reduction with photo-Fenton process for the removal of persistent pollutants. Chem. Eng. J. 2016, 310, 484-490. [CrossRef]

9. $\quad$ Li, M.; Mu, Y.; Shang, H.; Mao, C.; Cao, S.; Ai, Z.; Zhang, L. Phosphate modification enables high efficiency and electron selectivity of nZVI toward Cr(VI) removal. Appl. Catal. B Environ. 2020, 263, 118364. [CrossRef]

10. Brumovský, M.; Oborná, J.; Lacina, P.; Hegedüs, M.; Sracek, O.; Kolař́́k, J.; Petr, M.; Kašlík, J.; Hofmann, T.; Filip, J. Sulfidated nano-scale zerovalent iron is able to effectively reduce in situ hexavalent chromium in a contaminated aquifer. J. Hazard. Mater. 2021, 405, 124665. [CrossRef]

11. Li, Z.J.; Wang, L.; Yuan, L.Y.; Xiao, C.L.; Mei, L.; Zheng, L.R.; Zhang, J.; Yang, J.H.; Zhao, Y.L.; Zhu, Z.T.; et al. Efficient removal of uranium from aqueous solution by zero-valent iron nanoparticle and its graphene composite. J. Hazard. Mater. 2015, 290, 26-33. [CrossRef] [PubMed]

12. Chen, C.; Liu, J.; Gen, C.; Liu, Q.; Zhu, X.; Qi, W.; Wang, F. Synthesis of zero-valent iron/biochar by carbothermal reduction from wood waste and iron mud for removing rhodamine B. Environ. Sci. Pollut. Res. 2021, 28, 48556-48568. [CrossRef] [PubMed]

13. Sleiman, N.; Deluchat, V.; Wazne, M.; Mallet, M.; Courtin-Nomade, A.; Kazpard, V.; Baudu, M. Phosphate removal from aqueous solutions using zero valent iron (ZVI): Influence of solution composition and ZVI aging. Colloids Surf. A Physicochem. Eng. Asp. 2017, 514, 1-10. [CrossRef]

14. O'Carroll, D.; Sleep, B.; Krol, M.; Boparai, H.K.; Kocur, C. Nanoscale zero valent iron and bimetallic particles for contaminated site remediation. Adv. Water Resour. 2013, 51, 104-122. [CrossRef]

15. Vogel, M.; Georgi, A.; Kopinke, F.-D.; Mackenzie, K. Sulfidation of ZVI/AC composite leads to highly corrosion-resistant nanoremediation particles with extended life-time. Sci. Total Environ. 2019, 665, 235-245. [CrossRef]

16. Khan, A.; Prabhu, S.M.; Park, J.; Lee, W.; Chon, C.-M.; Ahn, J.S.; Lee, G. Azo dye decolorization by ZVI under circum-neutral pH conditions and the characterization of ZVI corrosion products. J. Ind. Eng. Chem. 2017, 47, 86-93. [CrossRef] 
17. Xu, H.; Sun, Y.; Li, J.; Li, F.; Guan, X. Aging of Zerovalent Iron in Synthetic Groundwater: X-ray Photoelectron Spectroscopy Depth Profiling Characterization and Depassivation with Uniform Magnetic Field. Environ. Sci. Technol. 2016, 50, 8214-8222. [CrossRef]

18. Xiaohong, L.; Guan, Z.; Shi, L. Coupled Effects of Aging and Weak Magnetic Fields on Sequestration of Selenste by Zero-Valent Iron. Environ. Sci. Technol. 2014, 48, 6326-6334.

19. Lu, X.; Li, M.; Tang, C.; Feng, C.; Liu, X. Electrochemical depassivation for recovering Fe0 reactivity by Cr(VI) removal with a permeable reactive barrier system. J. Hazard. Mater. 2012, 213-214, 355-360. [CrossRef]

20. Cheng, Y.; Dong, H.; Hao, T. $\mathrm{CaCO}_{3}$ coated nanoscale zero-valent iron (nZVI) for the removal of chromium(VI) in aqueous solution. Sep. Purif. Technol. 2021, 257, 117967. [CrossRef]

21. Dong, H.; Ning, Q.; Li, L.; Wang, Y.; Wang, B.; Zhang, L.; Tian, R.; Li, R.; Chen, J.; Xie, Q. A comparative study on the activation of persulfate by bare and surface-stabilized nanoscale zero-valent iron for the removal of sulfamethazine. Sep. Purif. Technol. 2020, 230, 115869. [CrossRef]

22. Ling, R.; Chen, J.P.; Shao, J.; Reinhard, M. Degradation of organic compounds during the corrosion of ZVI by hydrogen peroxide at neutral $\mathrm{pH}$ : Kinetics, mechanisms and effect of corrosion promoting and inhibiting ions. Water Res. 2018, 134, 44-53. [CrossRef] [PubMed]

23. Kim, H.-S.; Ahn, J.-Y.; Hwang, K.-Y.; Park, J.-Y.; Lim, T.-T.; Hwang, I.; Kim, T. Aging characteristics and reactivity of two types of nanoscale zero-valent iron particles $\left(\mathrm{FeBH}\right.$ and $\left.\mathrm{FeH}_{2}\right)$ in nitrate reduction. Chem. Eng. J. 2012, 197, 16-23. [CrossRef]

24. Pullin, H.; Springell, R.; Parry, S.; Scott, T. The effect of aqueous corrosion on the structure and reactivity of zero-valent iron nanoparticles. Chem. Eng. J. 2017, 308, 568-577. [CrossRef]

25. Jiang, Z.; Zhang, S.; Pan, B.; Wang, W.; Wang, X.; Lu, L.; Zhang, W.; Zhang, Q. A fabrication strategy for nanosized zero valent iron (nZVI)-polymeric anion exchanger composites with tunable structure for nitrate reduction. J. Hazard. Mater. 2012, 233-234, 1-6. [CrossRef] [PubMed]

26. Lace, A.; Ryan, D.; Bowkett, M.; Cleary, J. Chromium Monitoring in Water by Colorimetry Using Optimised 1,5-Diphenylcarbazide Method. Int. J. Environ. Res. Public Health 2019, 16, 1803. [CrossRef] [PubMed]

27. Ponder, S.M.; Darab, A.J.G.; Mallouk, T.E. Remediation of $\mathrm{Cr}(\mathrm{VI})$ and $\mathrm{Pb}(\mathrm{II})$ Aqueous Solutions Using Supported, Nanoscale Zero-valent Iron. Environ. Sci. Technol. 2000, 34, 2564-2569. [CrossRef]

28. Liu, H.; Gao, B.; Yuan, W.; Li, H.; Li, J.; Li, Y.; Zhang, B.; Chen, Z. Modification of graphene aerogel with titania nanotubes for efficient methylene blue adsorption kinetics. J. Sol-Gel Sci. Technol. 2021, 97, 271-280. [CrossRef]

29. Liu, F.; Zhang, X.; Shan, C.; Pan, B. Effect of 3-D distribution of ZVI nanoparticles confined in polymeric anion exchanger on EDTA-chelated Cu(II) removal. Environ. Sci. Pollut. Res. Int. 2019, 26, 10013-10022. [CrossRef]

30. Wang, Q.; Qian, H.; Yang, Y.; Zhang, Z.; Naman, C.; Xu, X. Reduction of hexavalent chromium by carboxymethyl cellu-losestabilized zero-valent iron nanoparticles. J. Contam. Hydrol. 2010, 114, 35-42. [CrossRef]

31. Huang, Y.H.; Zhang, T.C. Effects of low $\mathrm{pH}$ on nitrate reduction by iron powder. Water Res. 2004, 38, 2631-2642. [CrossRef] [PubMed]

32. Yang, Z.; Xu, H.; Shan, C.; Jiang, Z.; Pan, B. Effects of brining on the corrosion of ZVI and its subsequent As(III/V) and Se(IV/VI) removal from water. Chemosphere 2017, 170, 251-259. [CrossRef] [PubMed]

33. Yin, W.; Wu, J.; Ping, L.; Wang, X.; Zhu, N.; Wu, P.; Bo, Y. Experimental study of zero-valent iron induced nitrobenzene reduction in groundwater: The effects of $\mathrm{pH}$, iron dosage, oxygen and common dissolved anions. Chem. Eng. J. 2012, 184, 198-204. [CrossRef]

34. Skovbjerg, L.L.; Stipp, S.L.S.; Utsunomiya, S.; Ewing, R.C. The mechanisms of reduction of hexavalent chromium by green rust sodium sulphate: Formation of Cr-goethite. Geochim. Cosmochim. Acta 2006, 70, 3582-3592. [CrossRef]

35. Tian, Z.; Yuan, F.; Wei, M.; Chen, H.; Liu, F. Effects of nitrate on the removal of hexavalent chromium from groundwater by zero valent iron. J. Environ. Eng. 2017, 11, 4051-4058.

36. Xu, J.; Tan, L.; Baig, S.A.; Wu, D.; Lv, X.; Xu, X. Dechlorination of 2,4-dichlorophenol by nanoscale magnetic Pd/Fe particles: Effects of $\mathrm{pH}$, temperature, common dissolved ions and humic acid. Chem. Eng. J. 2013, 231, 26-35. [CrossRef]

37. Lv, X.; Hu, Y.; Tang, J.; Sheng, T.; Jiang, G.; Xu, X. Effects of co-existing ions and natural organic matter on removal of chromium (VI) from aqueous solution by nanoscale zero valent iron (nZVI)- $\mathrm{Fe}_{3} \mathrm{O}_{4}$ nanocomposites. Chem. Eng. J. 2013, 218, 55-64. [CrossRef]

38. Tanboonchuy, V.; Grisdanurak, N.; Liao, C.-H. Background species effect on aqueous arsenic removal by nano zero-valent iron using fractional factorial design. J. Hazard. Mater. 2012, 205-206, 40-46. [CrossRef]

39. Chen, S.Y.; Huang, S.W.; Chiang, P.N.; Liu, J.C.; Kuan, W.H.; Huang, J.H.; Hung, J.T.; Tzou, Y.M.; Chen, C.C.; Wang, M.K. Influence of chemical compositions and molecular weights of humic acids on $\mathrm{Cr}(\mathrm{VI})$ photo-reduction. J. Hazard. Mater. 2011, 197, 337-344. [CrossRef]

40. Mak, M.S.H.; Rao, P.; Lo, I.M.C. Effects of hardness and alkalinity on the removal of arsenic(V) from humic acid-deficient and humic acid-rich groundwater by zero-valent iron. Water Res. 2009, 43, 4296-4304. [CrossRef]

41. Fu, F.; Cheng, Z.; Dionysiou, D.D.; Tang, B. Fe/Al bimetallic particles for the fast and highly efficient removal of Cr(VI) over a wide $\mathrm{pH}$ range: Performance and mechanism. J. Hazard. Mater. 2015, 298, 261-269. [CrossRef] [PubMed]

42. Xu, C.; Yang, W.; Liu, W.; Sun, H.; Jiao, C.; Lin, A.J. Performance and mechanism of Cr(VI) removal by zero-valent iron loaded onto expanded graphite. J. Environ. Sci. 2017, 67, 17-25. [CrossRef] [PubMed] 